\title{
Wind tunnel experiments on cross-ventilation flow of a generic building with contaminant dispersion in unsheltered and sheltered conditions
}

\author{
Yoshihide Tominaga ${ }^{a,}{ }^{,}$and Bert Blocken ${ }^{\text {b,c }}$ \\ ${ }^{a}$ Department of Architecture and Building Engineering, Niigata Institute of Technology, 1719 Fujihashi, \\ Kashiwazaki, Japan \\ ${ }^{b}$ Department of the Built Environment, Eindhoven University of Technology, P.O.Box 5135600 MB \\ Eindhoven, The Netherlands \\ ${ }^{c}$ Department of Civil Engineering, Leuven University, Kasteelpark Arenberg 40 - bus 2447, 3001 Leuven, \\ Belgium \\ *Corresponding author: Tel \& Fax: +81 (0)257 22 8176, E-mail address: tominaga@abe.niit.ac.jp.
}

\section{Graphical abstract}

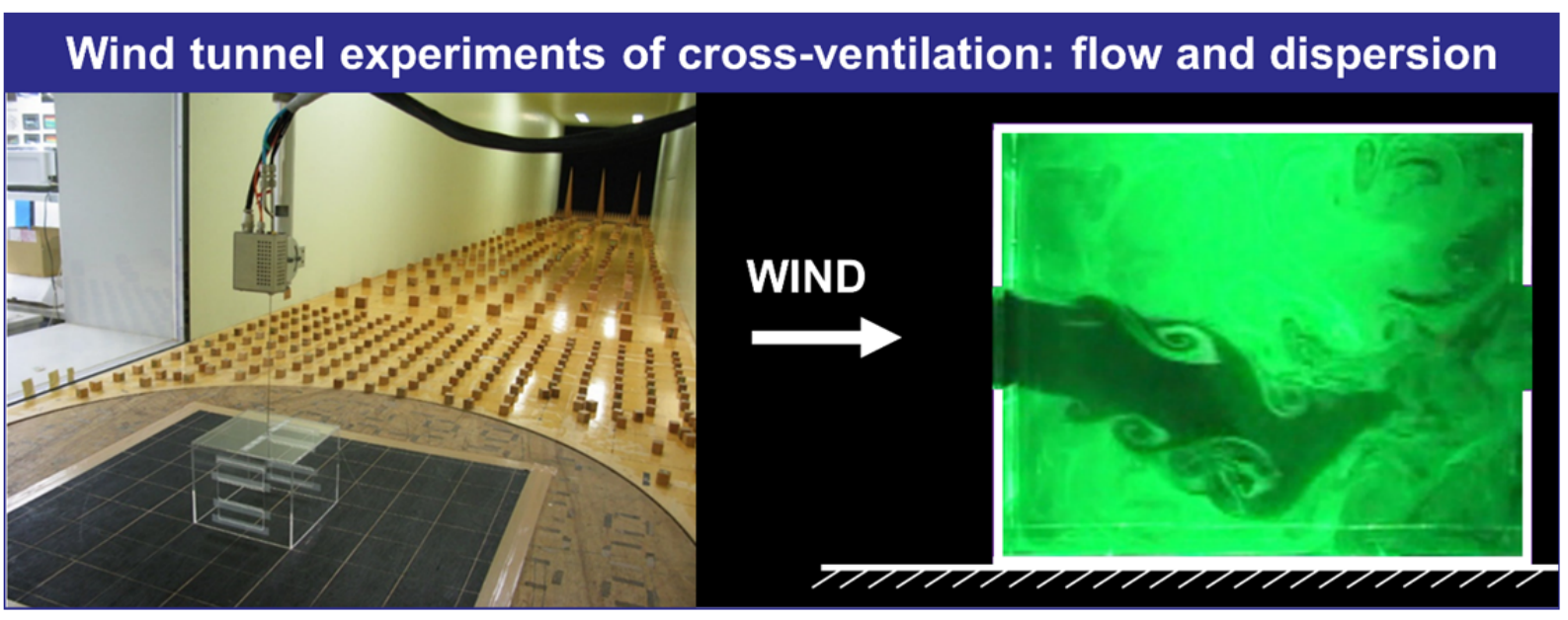

\section{Highlights}

- Detailed wind tunnel experiments were performed on a cross-ventilated building.

- Distributions of mean and fluctuating velocities and concentrations were measured.

- Unsheltered and sheltered conditions were evaluated.

- The sheltered building had a 70\% lower air flow rate than the unsheltered/isolated one.

- $\quad$ The data is intended to be used to validate CFD methods. 


\title{
Wind tunnel experiments on cross-ventilation flow of a generic building with contaminant dispersion in unsheltered and sheltered conditions
}

\author{
Yoshihide Tominaga $^{\mathrm{a},{ }^{*}}$ and Bert Blocken ${ }^{\mathrm{b}, \mathrm{c}}$ \\ ${ }^{a}$ Department of Architecture and Building Engineering, Niigata Institute of Technology, 1719 Fujihashi, \\ Kashiwazaki, Japan \\ ${ }^{b}$ Department of the Built Environment, Eindhoven University of Technology, P.O.Box 5135600 MB \\ Eindhoven, The Netherlands \\ ${ }^{c}$ Department of Civil Engineering, Leuven University, Kasteelpark Arenberg 40 - bus 2447, 3001 Leuven, \\ Belgium \\ * Corresponding author: Tel \& Fax: +81 (0)257 22 8176, E-mail address: tominaga@abe.niit.ac.jp.
}

\begin{abstract}
Recently, computational fluid dynamics (CFD) has been widely used for the prediction and analysis of cross-ventilation flows in buildings. In this study, detailed wind tunnel

experiments were performed on the cross-ventilation flow of a generic single-zone building in order to compile a validation database for CFD methods. Both the velocity fields and the contaminant concentration fields were measured and investigated. First, the fundamental characteristics of the velocity and concentration fields in a cross-ventilated flow were investigated for the building in unsheltered conditions. Next, the distributions of turbulent scalar fluxes in a cross-ventilated flow, which have been rarely reported, were also measured, and the scalar transport mechanism was examined based on the results. Finally, the effect of the surrounding buildings on the cross-ventilation flow was investigated. This study shows that the turbulent velocity fluctuations and concentration fluctuations are clearly generated by different mechanisms. These results can be used to effectively and successfully validate CFD methods applied to the flow and concentration fields of cross-ventilation flows.
\end{abstract}

\section{Keywords}

Wind tunnel experiment, Cross-ventilation, Contaminant dispersion, Validation, Experimental data set

\section{$1 \quad$ Introduction}

The cross-ventilation of buildings with large openings is characterized by intricate interactions between the outdoor wind flow around the building and the indoor air flow inside the building. Although numerous studies have been conducted using wind tunnel experiments and on-site measurements in order to grasp the complicated mechanism of cross-ventilation [1-10], this approach is limited in its ability to clarify such a complicated phenomenon because of its three-dimensionality, unsteadiness, multiplicity, and so on. Computational fluid dynamics (CFD) is an effective approach for overcoming such limitations and has already been used in many studies [11-17].

An additional clear merit of the CFD approach is that it can easily consider contaminant dispersion, which is sometimes difficult to capture with physical modeling because of limitations with regard to the measurement resolution and similarity constraints. Since one of the main purposes of cross-ventilation is removing pollutants and other environmental hazards that affect the indoor air quality, CFD simulation of cross-ventilation flows including contaminant dispersion is an important topic. Although several studies have analyzed the dispersion of $\mathrm{CO}_{2}$ or other tracer gases in cross-ventilated buildings using CFD [18-22], only 
few have compared their results with experimental data [21, 22]. Therefore, the performance of CFD analysis with regard to contaminant dispersion in a cross-ventilated building has not been clarified so far.

The accuracy and reliability of CFD simulations should be confirmed through validation and sensitivity studies, including solution verification [23-29]. Naturally, CFD simulations should be validated with high-quality experimental data. However, there have been very few studies on experimental measurements of the contaminant distribution in a cross-ventilated building [30,31]. Furthermore, previous experimental studies on cross-ventilation flow have mainly focused on the mean (time-averaged) velocities and rarely on the turbulent fluctuation inside the building, even though in cases of large openings, cross-ventilation is characterized by the preservation of the total kinetic energy (mean kinetic energy + turbulent kinetic energy) through openings [32]. Since the transport of pollutant concentration is known to be strongly influenced by the mean and turbulent flow fields, detailed experimental results on contaminant dispersion in a cross-ventilated flow in association with a velocity field should be provided to validate CFD methods.

In this study, detailed wind tunnel experiments were performed on the velocity and concentration fields in the cross-ventilation flow of a generic single-zone building in order to compile a validation database for CFD methods. The distributions of not only the velocity fields but also the contaminant concentration fields were measured and analyzed. Section 2 outlines the wind tunnel experiments. Section 3 presents the fundamental characteristics of the velocity and concentration fields in the cross-ventilated flow of the isolated (unsheltered) building. The distributions of the turbulent scalar fluxes, which have been rarely reported, are also presented, and the scalar transport mechanism is considered based on the results. Section 4 clarifies the effects of surrounding buildings on the cross-ventilation flow. Finally, Section 5 summarizes the findings of the present study and discusses future prospects.

\section{Outline of wind tunnel experiment}

\subsection{Building configuration}

A generic single-zone building with two opposite openings was considered. This configuration was made similar in shape to the model used in the extensive experiments by Karava et al. [7] so that the results could be compared. The 1:100 scale building model had dimensions $W \times D \times H=0.20 \mathrm{~m} \times 0.20 \mathrm{~m} \times 0.16 \mathrm{~m}$. Fig. 1 (a) indicates the size and location of the openings in the facades perpendicular to the wind direction. The opening positions were central in the windward and leeward facade, at height $h=80 \mathrm{~mm}$. Fig. 1(b) presents a perspective view. This configuration corresponds to 'Configuration E1' of the experiment by Karava et al. [7]. The area of one opening was $3.3 \times 10^{-3} \mathrm{~m}^{2}$ at reduced scale. A gas outlet, which has a dimension $8 \mathrm{~mm}(0.05 \mathrm{H}) \times 8 \mathrm{~mm}(0.05 \mathrm{H})$, was installed at the center of the floor.

Measurements were also taken under the condition that the cross-ventilated building was surrounded by buildings of the same size without openings, as indicated in Fig. 2. To investigate purely the influence of the adjacent building, only one block was arranged as a neighboring building in all directions, because surrounding buildings spread to the upwind direction would change the property of the approaching flow significantly. To minimize parameters to be considered, the surrounded buildings have no openings. The street widths were all equal to the building width $W$. 
The experiments were carried out in the atmospheric boundary layer wind tunnel at Niigata Institute of Technology [27, 33-35]. The test section is $13 \mathrm{~m}$ long, $1.8 \mathrm{~m}$ high, and 1.8 $\mathrm{m}$ wide. A combination of spires and surface roughness was used to create an approach-flow wind profile representative of the lower part of a neutral atmospheric boundary layer. Fig. 3 shows the experimental set-up for the concentration measurements. Fig. 4 shows the vertical profiles of the mean velocity $\bar{u}$ and turbulent kinetic energy $k$ for the incident flow, i.e. measured at the center of the empty turntable. The mean streamwise velocity of this approaching flow obeyed a power law with an exponent of 0.25 :

$\frac{U(z)}{U_{H}}=\left(\frac{z}{H}\right)^{0.25}$

where $U(z)$ and $U_{H}$ are the mean streamwise velocity at height $z$ and that at the reference height $H$, respectively.

The turbulent kinetic energy $k$ was exactly obtained by three-component measurement of the variances in the velocity fluctuations. This distribution can be approximated by the following relation:

$\frac{k(z)}{U_{H}^{2}}=0.033 \exp ^{-0.32\left(\frac{z}{H}\right)}$

The wind speed at the building height $H$ (i.e., $U_{\mathrm{H}}$ ) was measured to be $4.3 \mathrm{~m} / \mathrm{s}$, yielding a building Reynolds number of about 45,000. Due to the constraints on the concentration measurement, a lower velocity of $2.2 \mathrm{~m} / \mathrm{s}$ was required to measure the concentration in the preferred measurement range. This value corresponds to a building Reynolds number of about 23,000. These building Reynolds numbers are higher enough than the previously reported critical ones to obtain Reynolds-number independence [36]. The differences between the vertical profiles of $\bar{u}$ and $k$ with the two experimental velocities were within 5\%. The aerodynamic roughness length $z_{0}$, deduced from the line fitted to the mean velocity profile except for the effect of the internal boundary layer on the turntable, was $7 \times 10^{-3} \mathrm{~m}$. Appling this $z_{0}$ value to the logarithmic law, the friction velocity $u^{*}$ for the experimental conditions can be calculated as approximately 0.3 and $0.5 \mathrm{~m} / \mathrm{s}$, respectively. Therefore, the roughness Reynolds number [37] based on $z_{0}$ and $u^{*}$ were approximately 13 and 25 , respectively. It is confirmed that these experimental conditions satisfy the criteria for a fully rough surface [9, $36,37]$.

Ethylene $\left(\mathrm{C}_{2} \mathrm{H}_{4}\right)$, which has a density very similar to air, was used as the tracer gas. The emitted mass flow rate of the tracer gas was set to $2.0 \mathrm{~L} / \mathrm{min}$ for the concentration measurement. This flow rate corresponded to the emission velocity $W_{\mathrm{e}}$ of $0.52 \mathrm{~m} / \mathrm{s}$. Therefore, the emission velocity ratio $W_{\mathrm{e}} / U_{H}$ was 0.25 for the series of concentration measurements. The concentrations were expressed in non-dimensional form $C^{*}$, where the concentration $c$ is divided by the reference concentration $C_{0}$ given by:

$C_{0}=\frac{q_{e}}{H^{2} U_{H}}$

where $q_{\mathrm{e}}$ is the pollutant emission rate. 


\section{$2.3 \quad$ Measurements}

The wind velocity was measured with a split fiber probe (SFP) (Dantec Dynamics; 55R55) and constant temperature anemometry (CTA) module (Dantec Dynamics; 90C10) to identify the three-dimensional components of the velocity vector. The velocity time series of the three components were measured separately by changing the direction of the probe. Therefore, reverse flows in any axis could be measured. Time-averaging was conducted for a period of $60 \mathrm{~s}$ to obtain statistically stationary values with a sampling rate of $100 \mathrm{~Hz}$. The concentration was measured with a high-speed total hydrocarbon analyzer (Technica, HTHCA-01) in order to examine the air flow rate and dispersion properties. The initial concentration was zero for each experimental run. The samplings for obtaining statistical values were started after confirming that concentrations were statistically steady. The concentration resolution and time response of the hydrocarbon analyzer are $10 \mathrm{ppm}$ and 25 ms, respectively.

Fig. 5 shows the location of the measurement points in the vertical center section. The variables were measured at each point by the insertion of the measurement probe and sampling tube through the holes along the centerline on the ceiling of the building model. Unused holes and interspaces were always sealed with tape during the measurements. The diameters of the support for the SFP and the sampling tube of the total hydrocarbon analyzer were $6 \mathrm{~mm}$ and $1 \mathrm{~mm}$, respectively.

The air flow rate was measured using the tracer gas method, separately from the detailed measurement for the concentration distributions. The tracer gas, which was also ethylene, was released from appropriate positions near the inlet opening so that it would be well-mixed inside the building model. By considering stationary conditions, the air flow rate $Q\left[\mathrm{~m}^{3} / \mathrm{s}\right]$ can be obtained by

$Q=\frac{q_{\text {inlet }}}{\overline{c_{\text {outlet }}}}$

where $q_{\text {inlet }}\left[\mathrm{m}^{3} / \mathrm{s}\right]$ is the gas emission rate at the inlet openings and $\overline{c_{\text {outlet }}}\left[\mathrm{m}^{3} / \mathrm{m}^{3}\right]$ is the timeaveraged concentration measured at the outlet openings for $60 \mathrm{~s}$. Repeatability checks were carried out for different release points and the uncertainty of the air flow rate was estimated to be within approximately $\pm 7 \%$.

Turbulent scalar fluxes were obtained by directly measuring the instantaneous velocities and concentrations simultaneously following the method proposed by Yoshie et al. [38]. For this measurement, the sensors were placed at about $2 \mathrm{~mm}$ intervals so that the SFP and the sampling tube did not affect each other's measurements. The time series of the concentrations was shifted by $25 \mathrm{~ms}$ to express the delay between the suction of the sample air into the sampling tube and the moment of sample analysis. For example, the streamwise component of the turbulent scalar flux $\overline{u^{\prime} c^{\prime}}$ can be calculated as follows:

$\overline{u^{\prime} c^{\prime}}=\overline{u \cdot c_{\text {shifted }}}-\bar{u} \cdot \bar{c}$

Here, the line on top expresses time-averaged values; $u$ is the instantaneous streamwise velocity, $c$ is the instantaneous concentration, and $c_{\text {shifted }}$ is the time-delayed instantaneous concentration. 


\subsection{Flow visualization}

Fig. 6 provides 16 images of flow visualization in the vertical center section of the unsheltered building. These were obtained as follows. First, the wind tunnel was started until statistically stationary flow conditions in the building were obtained. The wind speed at roof height $U_{H}$ was $1.7 \mathrm{~m} / \mathrm{s}$, i.e. slightly lower than for the concentration measurements, in order to optimize visibility. Next, while running the tunnel, smoke (evaporated oil) from a smoke generator was gradually injected into the building from the roof. Finally, the smoke insertion was removed and camera shots were taken at a frequency of $30 \mathrm{~Hz}$. Fig. 6 shows 16 shots, each $1 \mathrm{~s}$ apart. The first shot was taken $1 \mathrm{~s}$ after the end of the smoke injection, and the 16 images show the removal of the smoke by cross-ventilation over a period of 16 s. Fig. 6 also clearly shows some main characteristics of the ventilation flow. It is well-known in wind engineering that the turbulent flow around buildings is highly unsteady with separation, recirculation and von Karman vortex shedding in the wake (e.g. [39-41]). The present study shows a similarly large degree of unsteadiness inside the cross-ventilated building and provides insight into the transient behavior of the ventilation jet as well as the overall indoor flow field. Although the incoming jet flow is on average directed downwards, it is clearly a so-called flapping jet and its direction varies in time between horizontal and inclined downwards with a maximum angle of about $60^{\circ}$. In addition, the jet is characterized by clear and very pronounced Kelvin-Helmholz instability leading to the formation and shedding of discrete vertical structures. The jet Reynolds number, based on the inlet wind speed and the hydraulic diameter of the inlet opening, is about 3,000. Similar observations Kelvin-Helmholz instability were observed in experimental studies of a cubical enclosure ventilated by a wellconditioned transitional inlet jet $[42,43]$. The present study shows that even in crossventilation and hence much more complex and more turbulent approach flow, and with a flapping jet, very pronounced Kelvin-Helmholz instabilities are present, which occupy the whole interior of the building. As vortical structures are shed from the jet, they subsequently impinge on either the floor, ceiling or opposing wall.

\subsection{Velocity field}

Fig. 7 compares the streamwise velocity ratio $\bar{u} / U_{\mathrm{H}}$ along the centerline to that obtained from the particle image velocimetry (PIV) measurements by Karava et al. [7]. The results of the two experiments show reasonable agreement, although their inflow conditions were not entirely identical. Thus, the similarity of the two experiments was confirmed.

Fig. 8 shows the time-averaged streamlines in the vertical center section and in a horizontal section at mid-height of the building. The incoming flow through the inlet opening went down into the room and discharged upward through the leeward opening. Two vertical recirculation flows (i.e., a clockwise flow just below the inlet opening and anti-clockwise flow in the upper half of the room) were detected. The general flow pattern also corresponded well to that obtained by Karava et al. [7]. Ramponi and Blocken [44] clarified that the turbulent kinetic energy of the approaching flow has a strong influence on the direction of the incoming jet through the inlet opening. Fig. 9 (a) indicates the vertical profiles of the timeaveraged streamwise velocity $\bar{u} / U_{H}$. The large $\bar{u}$ values around the incoming jet through the inlet opening were observed to gradually decay in the streamwise direction. Therefore, the velocity gradients $\partial \bar{u} / \partial z$ were large around the jet and rather small in other areas inside the room. Fig. 9 (b) shows the turbulent kinetic energy $k$ at the same measurement points. In general, the $k$ values were large where the velocity gradient $\partial \bar{u} / \partial z$ was large, as shown in Fig. 
9 (a). Based on this result, the turbulence inside the room was mainly produced by the velocity gradient around the jet as realized by the form of the production term in the $k$ equation: $-\overline{u_{i}^{\prime} u_{j}^{\prime}} \frac{\partial \overline{u_{i}}}{\partial x_{j}}$. This caused the $k$ produced around the jet to be dominant in the crossventilated room, which is consistent with the $k$ distributions predicted by Kobayashi et al. [45] using CFD.

\subsection{Concentration fields}

Fig. 10 shows the contours of the time-averaged concentration $C^{*}=\bar{c} / C_{0}$ in the vertical center section and in the horizontal section at mid-height. Note that the scale of both colorbars is different to highlight the concentration gradients. The contaminant was transported from the source towards the leeward opening by the mean flow, as shown in Fig. 8 (a). The contaminant diffusion in the vertical direction was not very large. Therefore, a large difference in the concentration was observed depending on the location in the room. Fig. 11 (a) shows the vertical profiles of the time-averaged concentrations $\bar{c} / C_{0}$. The absolute value of the concentration gradient in the vertical direction $\partial \bar{c} / \partial z$ was very large just above the gas source on the floor. Fig. 11 (b) shows the root-mean-square (RMS) values of the concentration fluctuations $\sqrt{\overline{c^{\prime 2}}} / C_{0}$. In general, the concentration fluctuations tend to be large where the spatial gradient of the mean concentration is large. A similar tendency for the distribution of $\sqrt{\overline{c^{\prime 2}}} / C_{0}$ was reported in the experimental results of the concentration measured in a street canyon flow [46]. Because the production term of the transport equation for $\overline{c^{\prime 2}}$ is expressed as $-\overline{u_{i}{ }^{\prime} \mathrm{c}^{\prime}} \frac{\partial \bar{c}}{\partial \mathrm{x}_{i}}$, the large negative mean concentration gradient $\partial \bar{c} / \partial z$ near the source contributes to the large production of $\overline{c^{\prime 2}}$. Note that the distributions of $k$ and $\overline{c^{\prime 2}}$ are completely different. This suggests that the turbulent fluctuations of velocity and concentration are generated by different mechanisms, namely, the turbulent fluctuations of velocity are mainly generated by the velocity shears around the incoming jet, while those of concentration are mainly produced by the mean concentration gradient.

\subsection{Advective and turbulent scalar flux}

Fig. 12 compares the vertical profiles of the advective fluxes $\left(\bar{u} \cdot \bar{c} / U_{H} C_{0}\right.$ and $\bar{w} \cdot \bar{c}$ / $\left.U_{H} C_{0}\right)$ and turbulent scalar fluxes $\left(\overline{u_{\imath}{ }^{\prime} c^{\prime}} / U_{H} C_{0}\right.$ and $\left.\overline{w^{\prime} c^{\prime}} / U_{H} C_{0}\right)$. The prediction accuracy of the scalar fluxes is very important to predicting the contaminant transport using CFD simulations. Although both fluxes showed large values just above the source, the streamwise component $(\bar{u} \cdot \bar{c})$ was slightly larger than the vertical component $(\bar{w} \cdot \bar{c})$ in the advective fluxes (Fig. 12 (a)). However, the vertical component $\left(\overline{w^{\prime} c^{\prime}}\right)$ was 8.5 times larger than the streamwise component $\left(\overline{u^{\prime} c^{\prime}}\right)$ in the turbulent scalar fluxes (Fig. $\left.12(\mathrm{~b})\right)$ at the nearest point to the source. It should be pointed out that the vertical component of the advective flux $(\bar{w} \cdot \bar{c})$ shows the opposite sign of that of the turbulent scalar flux $\left(\overline{w^{\prime} c^{\prime}}\right)$ and both offset each other near the source. This is closely related to the large concentration gradient just above the source, as noted earlier. 


\subsection{Air flow rate}

The dimensionless air flow rate $Q / U_{\mathrm{H}} A_{\text {inlet }}$ for the unsheltered building was 0.25 . This value was $37 \%$ smaller than that for the same configuration reported in Karava et al. [7]. It should be noted that the air flow rate reported in ref. [7] was calculated as $U_{\text {opening }} \cdot A$, where $U_{\text {opening }}$ is the area-averaged velocity downstream $(1 \mathrm{~cm})$ the inlet opening measured on a horizontal mid-plane (using the PIV technique), and A is the geometric area of the opening. Thus, it might be slightly different than the total air flow rate through the building and should be considered as part of the measurement uncertainty as the authors mentioned themselves [7]. On the other hand, for the sheltered building the air flow rate was only 0.07 , which implies a reduction to approximately $30 \%$ in the sheltered case due to the presence of the surrounding buildings. This is because the driving force of the ventilation was decreased by the small pressure difference acting on the upwind and leeward sides of the building from the sheltering effect [47]. Van Hooff and Blocken [48] reported that excluding the surrounding buildings can lead to an overestimation of the air flow rate with up to $96 \%$ based on their CFD results for the natural ventilation of a large semi-enclosed stadium. The present results support their findings, and the larger difference in the air flow rates can be explained by the fact that the openings were directly sheltered and the surrounding buildings were relatively large and the separation distances relatively small in the present study.

\subsection{Velocity and concentration fields}

Fig. 13 shows the time-averaged streamlines and contours of the time-averaged concentrations for the sheltered building. In contrast to the isolated case, the incoming flow through the inlet opening was not clearly observed. Because of the vortex between the upwind building and target building (which was not measured but observed by flow visualization), the incoming jet had a strong downward orientation into the room, and a large anti-clockwise recirculation flow formed in the entire room. Therefore, the concentration was mainly dispersed in the vertical direction, and the concentration was approximately 8 times higher in the spatial average than in the isolated case, as shown in Fig. 10.

Fig. 14 (a) compares the distributions of the turbulent kinetic energy $k$ obtained for the isolated and sheltered cases. The value of $k$ was $43 \%$ smaller in the sheltered case than in the isolated case in the spatial average. Except for just below the inlet opening, $k$ showed no peaks in the room. This is because no clear jet blew through the inlet opening in this case. On the other hand, the RMS values of the concentration fluctuations given in Fig. 14 (b) showed similar distribution patterns for both cases, and the values were larger for the sheltered case than for the isolated case. This suggests that the concentration fluctuations are generated by the large-scale flow patterns that form inside the room, not the turbulent fluctuation of the incoming flow.

\section{$5 \quad$ Summary and conclusions}

In this study, detailed wind tunnel experiments were performed on the cross-ventilation flow of a generic building in order to compile a validation database for CFD. Not only the mean velocity but also the turbulent fluctuation and contaminant concentration were measured for the building in unsheltered and sheltered conditions. To the best of the authors' knowledge, the availability in the literature of experimental data for CFD validation of cross- 
ventilation flow is very scarce. Although previous reports have indicated the importance of turbulent diffusion in cross-ventilated flow, the vast majority of experiments on crossventilated flow were conducted for a time-averaged velocity field. Consequently, there is a lack of experimental data on the turbulent properties and contaminant dispersion in a crossventilated flow to validate CFD models.

From the analysis of the time-averaged and fluctuating velocity and concentration for the unsheltered building, the following results are obtained:

- The time-averaged velocity field obtained in the present study showed reasonable agreement with that obtained in a previous experiment by Karava et al. [7]; thus, the similarity of the two experiments was confirmed.

- The relationship between the time-averaged velocity field and turbulent kinetic energy $k$ distributions was clarified. The $k$ values were large where the velocity gradient $\partial \bar{u} / \partial z$ was large. The values of $k$ in the room were mainly dominated by those produced by the large velocity gradient around the incoming jet.

- The concentration distribution was strongly affected by the flow pattern, and large differences in the time-averaged concentrations occurred depending on the location in the room. The concentration fluctuations were large where the spatial gradients of the mean concentrations were large. Therefore, the distributions of $k$ and $\overline{c^{\prime 2}}$ were completely different. This suggests that the fluctuations in the turbulent velocity and concentration are generated by different mechanisms.

- The measured advective fluxes and turbulent scalar fluxes were compared. Although both fluxes showed large values just above the gas outlet, the advective fluxes had a larger streamwise component than vertical component, while the opposite was true for the turbulent scalar fluxes. This result is closely related to the large concentration gradient just above the source.

The effect of the surrounding buildings on the cross-ventilated flow was also investigated. The obtained findings are as follows:

- The air flow rate was reduced to approximately $30 \%$ for the sheltered building due to the presence of the surrounding buildings. Moreover, the velocity and concentration fields for the sheltered building dramatically changed from those for the isolated case.

- Because of the surrounding buildings, the turbulent kinetic energy for the sheltered case was less than that for the isolated case. However, the concentration fluctuation for the sheltered case was greater than that for the isolated case. This indicates that the concentration fluctuations are generated by the large-scale flow patterns that form inside the building, not the turbulent fluctuations exerted by the incoming flow.

The present experiment had the following limitations.

- The measurement points were rather limited to facilitate operating efficiency, and the measurement resolution was not very high.

- This study was only performed for one building configuration and only for wind direction perpendicular to the windward facade.

Even if these discrepancies are considered, the experimental data still have value because comprehensively measuring the time-averaged and fluctuating velocity and concentration fields using non-intrusive measurement techniques like particle image velocimetry (PIV) is difficult.

This study was a first step in a more extensive research project on the turbulent diffusion mechanism in cross-ventilated flows using experimental and numerical approaches. The experimental dataset provided in this paper, especially the fluctuation properties of the 
velocity, concentration, and scalar fluxes, will have a significant beneficial effect on the validation of CFD simulations.

\section{Acknowledgments}

The framework of this paper was developed during the period that the first author visited the Department of the Built Environment, Eindhoven University of Technology, the Netherlands in September 2013. The authors would like to express their gratitude to the Obayashi Foundation for supporting this visit. This work was also financially supported by LIXIL JS Foundation (No. 14-38). The authors also thank Mr. Ryo Saito, an undergraduate student at the Niigata Institute of Technology, for his invaluable assistance with the experiments.

\section{References}

[1] Etheridge DW, Nolan J. Ventilation measurements at model scale in a turbulent flow. Build Environ $1979 ; 14: 53-64$.

[2] Murakami S, Kato S, Akabayashi S, Mizutani K, Kim Y. Wind tunnel test on velocity-pressure field of cross-ventilation with open windows. ASHRAE Trans 1991;97:525-38.

[3] Linden PF. The fluid mechanics of natural ventilation. Annu Rev Fluid Mech 1999;31:201-38.

[4] Ohba M, Irie K, Kurabuchi T. Study on airflow characteristics inside and outside a cross-ventilation model, and ventilation flow rates using wind tunnel experiments. J Wind Eng Ind Aerodyn 2001;89(1415):1513-1524.

[5] Tablada A, De Troyer F, Blocken B, Carmeliet J, Verschure H. On natural ventilation and thermal comfort in compact urban environments: The Old Havana case. Build Environ 2009;44:1943-58.

[6] Chu CR. Chiu YH. Chen YJ. Wang YW. Chou CP. Turbulence effects on the discharge coefficient and mean flow rate of wind-driven cross ventilation. Build Environ 2009;44:2064-2072.

[7] Karava P, Stathopoulos T, Athienitis AK. Airflow assessment in cross-ventilated buildings with operable façade elements. Build Environ 2011; 46(1):266-79.

[8] Ji L, Tan H, Kato S, Bu Z, Takahashi T. Wind tunnel investigation on influence of fluctuating wind direction on cross natural ventilation. Build Environ 2011;46:2490-2499.

[9] Zaki SA. Hagishima A. Tanimoto J. Experimental study of wind-induced ventilation in urban building of cube arrays with various layouts. J Wind Eng Ind Aerodyn 2012;103:31-40.

[10] Tecle A. Bitsuamlak GT. Jiru TE. Wind-driven natural ventilation in a low-rise building: A boundary layer wind tunnel study. Build Environ 2013;59:275-289.

[11] Chen Q. Ventilation performance prediction for buildings: A method overview and recent applications. Build Environ 2009; 44(4):848-58.

[12] Ohba M, Lun I. Overview of natural cross-ventilation studies and the latest simulation design tools used in building ventilation-related research. Adv Build Energ Res 2010;4:127-66.

[13] Jiru TE, Bitsuamlak GT, Application of CFD in modelling wind-induced natural ventilation of buildings - A review. Int J Vent 2010;9(2):131-47.

[14] Ramponi R. Blocken, B. CFD simulation of cross-ventilation for a generic isolated building: Impact of computational parameters. Build Environ 2012;53:34-48.

[15] Stavridou AD. Prinos PE. Natural ventilation of buildings due to buoyancy assisted by wind: Investigating cross ventilation with computational and laboratory simulation. Build Environ 2013; 66: 104-119.

[16] Chu CR. Chiang BF. Wind-driven cross ventilation in long buildings, Build Environ 2014; 80: 150-158.

[17] Perén JI. van Hooff T. Leite BCC. Blocken B. CFD analysis of cross-ventilation of a generic isolated building with asymmetric opening positions: Impact of roof angle and opening location, Build Environ 2015; 85: 263-276.

[18] Liu X, Niu J, Perino M, Heiselberg P. Numerical simulation of inter-flat air cross-contamination under the condition of single-sided natural ventilation. J Build Perform Simu 2008;1(2):133-47.

[19] Bartzanas T, Boulard T, Kittas C. Effect of vent arrangement on windward ventilation of a tunnel greenhouse. Biosyst Eng 2004;88(4):479-90.

[20] Bartzanas T, Kittasa C, Sapounasc AA, Nikita-Martzopoulouc C. Analysis of airflow through experimental rural buildings: Sensitivity to turbulence models. Biosyst Eng 2007;97:229-39. 
[21] Norton T, Grant J, Fallon R, Sun D-W. Assessing the ventilation effectiveness of naturally ventilated livestock buildings under wind dominated conditions using computational fluid dynamics. Biosyst Eng 2009;103(1):78-99.

[22] van Hooff T, Blocken B. CFD evaluation of natural ventilation of indoor environments by the concentration decay method: $\mathrm{CO}_{2}$ gas dispersion from a semi-enclosed stadium. Build Environ 2013;61:1-17.

[23] Blocken B, Gualtieri C. Ten iterative steps for model development and evaluation applied to computational fluid dynamics for environmental fluid mechanics. Environ Modell Softw 2012;33:1-22.

[24] Casey, M., Wintergerste, T. Best Practice Guidelines, ERCOFTAC Special Interest Group on Quality and Trust in Industrial CFD, ERCOFTAC, Brussels; 2000.

[25] Tominaga, Y., Mochida, A., Yoshie, R., Kataoka, H., Nozu, T., Yoshikawa, M., Shirasawa, T. AIJ guidelines for practical applications of CFD to pedestrian wind environment around buildings. J Wind Eng Ind Aerodyn 2008;96(10-11):1749-1761.

[26] Tominaga Y, Stathopoulos T. CFD simulation of near-field pollutant dispersion in the urban environment: A review of current modelling techniques. Atmos Environ 2013;79:716-730.

[27] Yoshie R, Mochida A, Tominaga Y, Kataoka H, Harimoto K, Nozu T, Shirasawa T. Cooperative project for CFD prediction of pedestrian wind environment in the Architectural Institute of Japan. J Wind Eng Ind Aerodyn 2007;95(9-11):1551-1578.

[28] Franke, J., Hellsten, A., Schl?nzen, H., Carissimo, B. (Eds.). Best practice guideline for the CFD simulation of flows in the urban environment. COST Office Brussels, ISBN 3-00-018312-4; 2007

[29] Blocken B. 50 years of Computational Wind Engineering: Past, present and future. J Wind Eng Ind Aerodyn 2014;129: 69-102.

[30] Ikeguchi A, Okushima L, Zhang G, Strom JS. Contaminant air propagation between naturally ventilated scale model pig buildings under steady-state conditions. Biosyst Eng 2005;90(2):217-26.

[31] van Hooff T, Blocken B. Full-scale measurements of indoor environmental conditions and natural ventilation in a large semi-enclosed stadium: Possibilities and limitations for CFD validation. J Wind Eng Ind Aerodyn 2012;104-106:330-41.

[32] Kato S, Murakami S, Mochida A, Akabayashi S, Tominaga Y. Velocity-pressure field of cross ventilation with open windows analyzed by wind tunnel and numerical simulation. J Wind Eng Ind Aerodyn 1992;44:2575-86.

[33] Akabayashi S, Mochida A, Tominaga Y,Yoshida M, Sakaguchi J. Performance of new wind tunnel of Niigata Institute of Technology, JWE 1996: 68: 95-106. [In Japanese]

[34] Kubota, T., Miura, M., Tominaga, Y., Mochida, A. Wind tunnel tests on the relationship between building density and pedestrian-level wind velocity: Development of guidelines for realizing acceptable wind environment in residential neighborhoods, Build Environ 2008: 43(10): 1699-1708.

[35] Tominaga, Y., Stathopoulos, T., CFD modeling of pollution dispersion in a street canyon: Comparison between LES and RANS, J Wind Eng Ind Aerodyn 2011: 99(4): 340-348.

[36] Uehara K. Wakamatsu S. Ooka R. Studies on critical Reynolds number indices for wind-tunnel experiments on flow within urban areas. Bound.-Layer Meteor., 2003;107:353-370.

[37] Snyder WH. Castro IP. The critical Reynolds number for rough-wall boundary layers, J Wind Eng Ind Aerodyn 2002;90:41-54.

[38] Yoshie R, Tanaka H, Shirasawa T. Technique for simultaneously measuring fluctuating velocity, temperature and concentration in non-isothermal flow. In: Proceedings of the 12th International Conference on Wind Engineering 2007;1399-1406.

[39] Castro IP, Robins AG. The flow around a surface-mounted cube in uniform and turbulent streams. J Fluid Mech 1977;79(2):307-335.

[40] Murakami, S. Comparison of various turbulence models applied to a bluff body. J Wind Eng Ind Aerodyn, 1993;46\&47:21-36.

[41] Tominaga, Y., Mochida, A., Murakami, S., Sawaki, S. Comparison of various revised k- $\varepsilon$ models and LES applied to flow around a high-rise building model with 1:1:2 shape placed within the surface boundary layer. J Wind Eng Ind Aerodyn, 2008;96(4): 389-411.

[42] van Hooff T, Blocken B, Defraeye T, Carmeliet J, van Heijst GJF. PIV measurements and analysis of transitional flow in a reduced-scale model: ventilation by a free plane jet with Coanda effect. Build Environ 2012;56:301-313.

[43] van Hooff T, Blocken B, Defraeye T, Carmeliet J, van Heijst GJF. PIV measurements of a plane wall jet in a confined space at transitional slot Reynolds numbers. Experiments in Fluids 2012;53:499-517.

[44] Ramponi R, Blocken B. CFD simulation of cross-ventilation flow for different isolated building configurations: Validation with wind tunnel measurements and analysis of physical and numerical diffusion effects. J Wind Eng Ind Aerodyn 2012;104-106:408-18.

[45] Kobayashi T, Sagara K, Yamanaka T, Kotani H, Sandberg M. Power transportation inside stream tube of cross-ventilated simple shaped model and pitched roof house, Build Environ 2009;44(7):1440-51. 
[46] Pavageau M, Schatzmann M. Wind tunnel measurements of concentration fluctuations in an urban street canyon. Atmos Environ 1999;33:3961-71.

[47] Cóstola D, Blocken B, Hensen JLM. Overview of pressure coefficient data in building energy simulation and airflow network programs. Build Environ 2009;44(10):2027-36.

[48] van Hooff T, Blocken B. On the effect of wind direction and urban surroundings on natural ventilation of a large semi-enclosed stadium. Comput Fluids 2010;39(7):1146-55.

\section{Nomenclature}

$x_{i} \quad:$ three components of spatial coordinate $(i=1$, streamwise $(x) ; i=2$, lateral $(y) ; i=3$, vertical $(z))$

$u_{i} \quad:$ three components of velocity vector $(i=1$, streamwise $(u) ; i=2$, lateral $(v) ; i=3$, vertical $(w))$

c : concentration.

$C_{0} \quad:$ reference concentration, $C_{0}=\frac{q_{e}}{H^{2} U_{H}}$

$q_{e} \quad$ : pollutant emission rate.

$f \quad$ : instantaneous value of quantity.

$\bar{f} \quad$ : time-averaged value of $f$

$f^{\prime} \quad$ : fluctuation of $f\left(\boldsymbol{f}^{\prime}=\boldsymbol{f}-\overline{\boldsymbol{f}}\right)$

$H \quad$ : height of building.

$k \quad$ : turbulent kinetic energy, $\boldsymbol{k}=\frac{1}{2}\left(\overline{\boldsymbol{u}^{\prime 2}}+\overline{\boldsymbol{v}^{\prime 2}}+\overline{\boldsymbol{w}^{\prime 2}}\right)$.

$U_{H} \quad:$ value of $\overline{\boldsymbol{u}}$ at height $H$ at inlet of computational domain. 


\section{Figures}

a

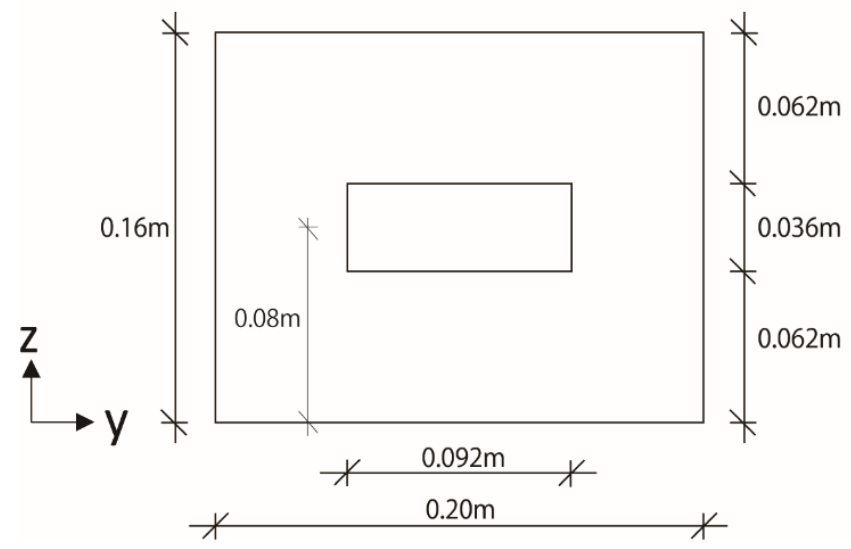

b

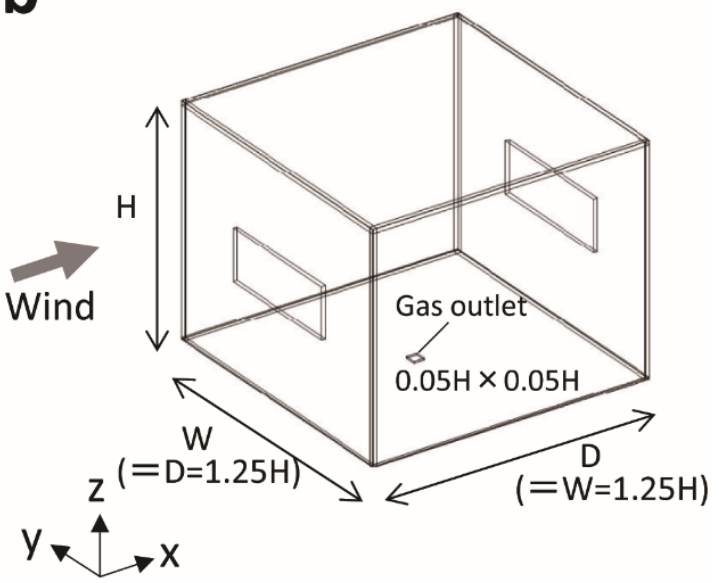

Fig. 1. (a) Front view and (b) perspective view of building model.

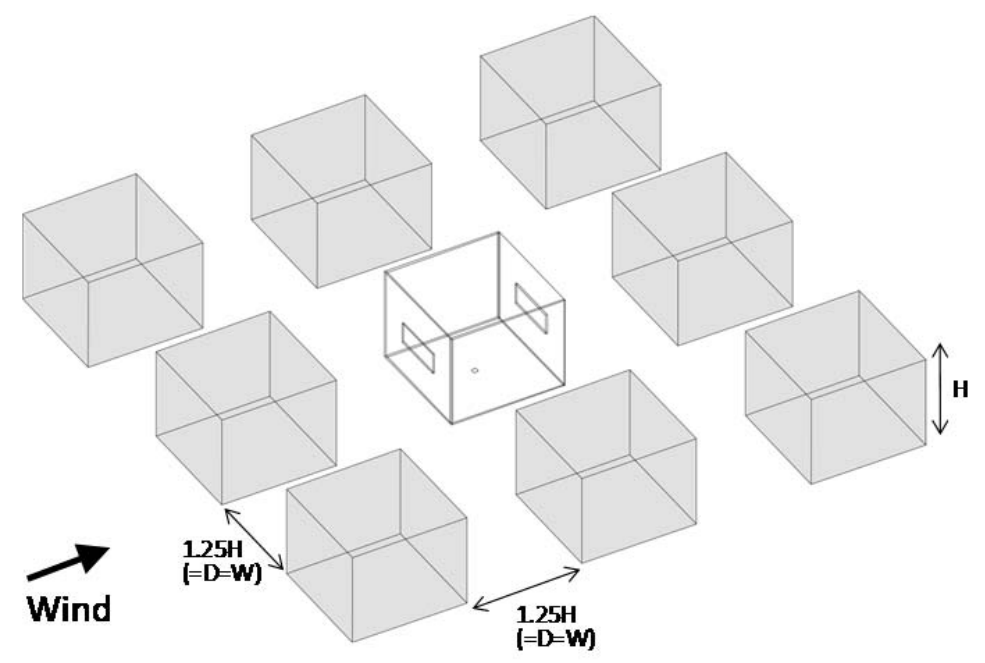

Fig. 2. Configuration of sheltered building case. 

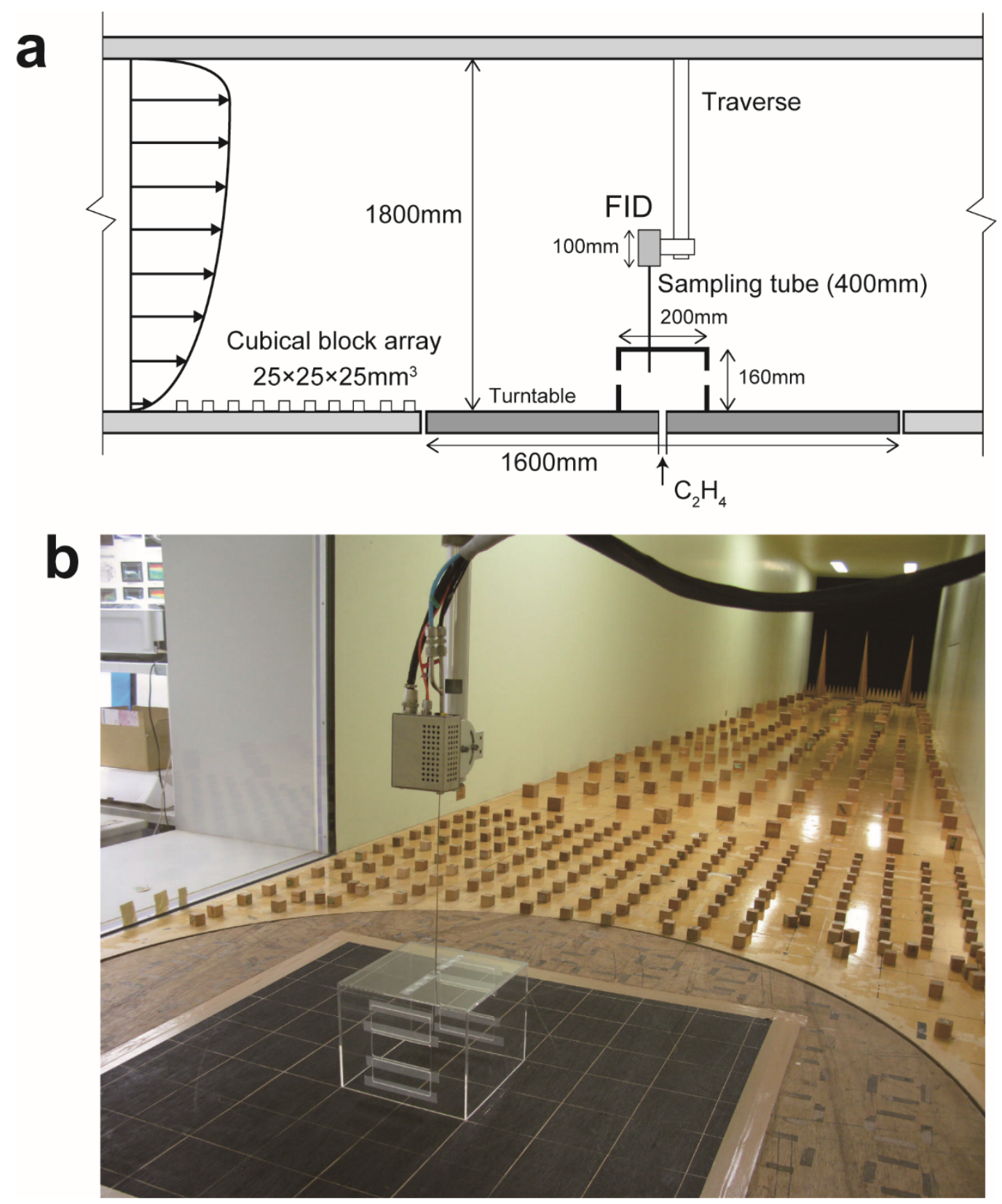

Fig. 3 Experimental set-up in wind tunnel for the concentration measurements: (a) Schematic side view and (b) Photo. 

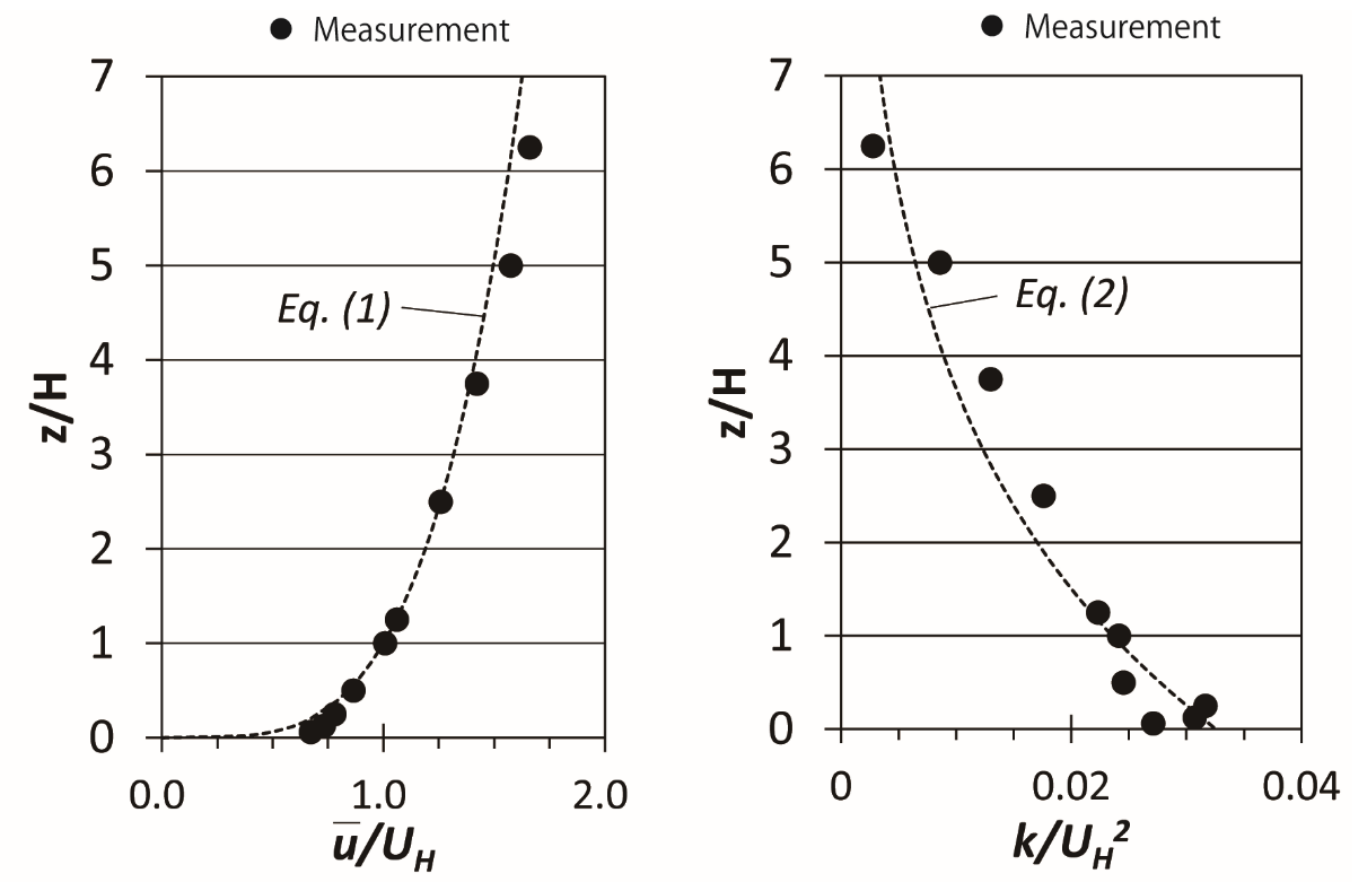

Fig. 4. Incident profiles of mean velocity $\bar{u}$ and turbulent kinetic energy $k$.

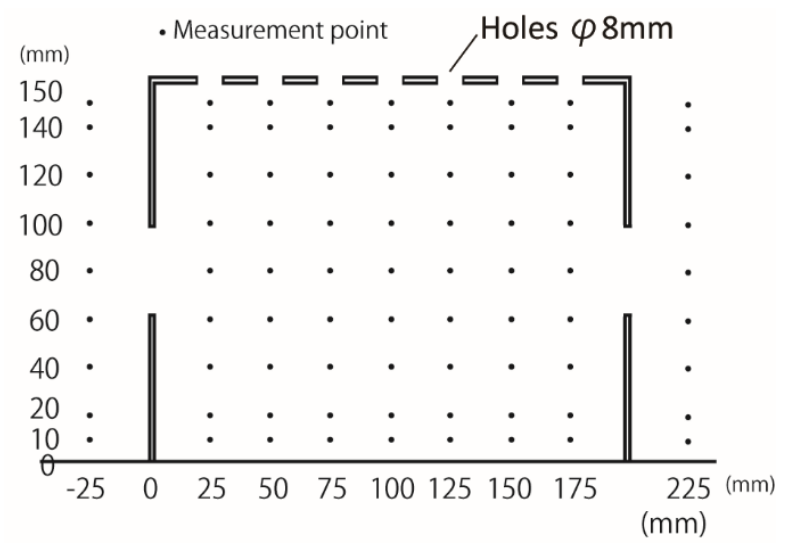

Fig. 5 Measurement points in vertical center section. 


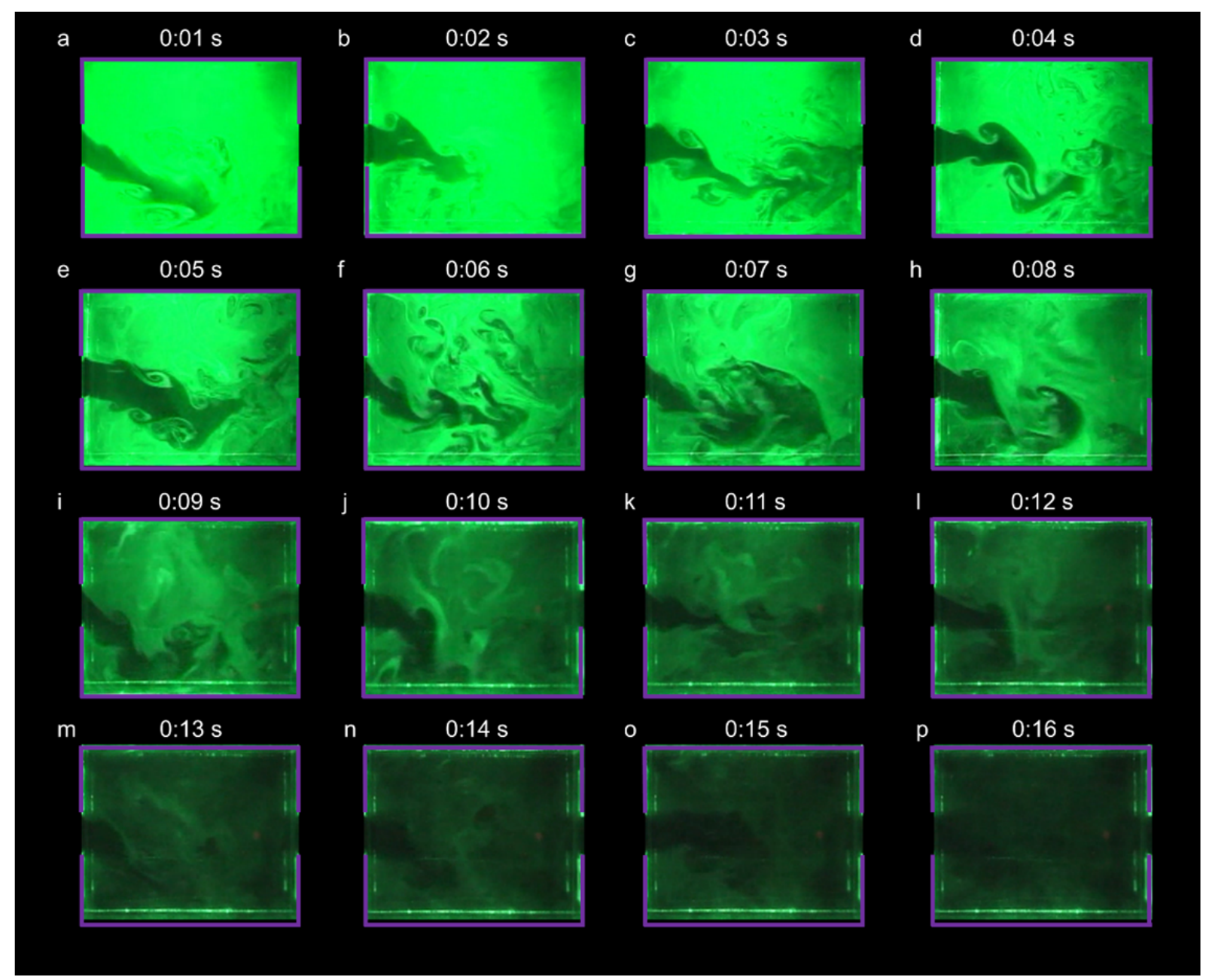

Fig. 6. Flow visualization in vertical center section of unsheltered building. Time interval between consecutive images is $1 \mathrm{~s}$.

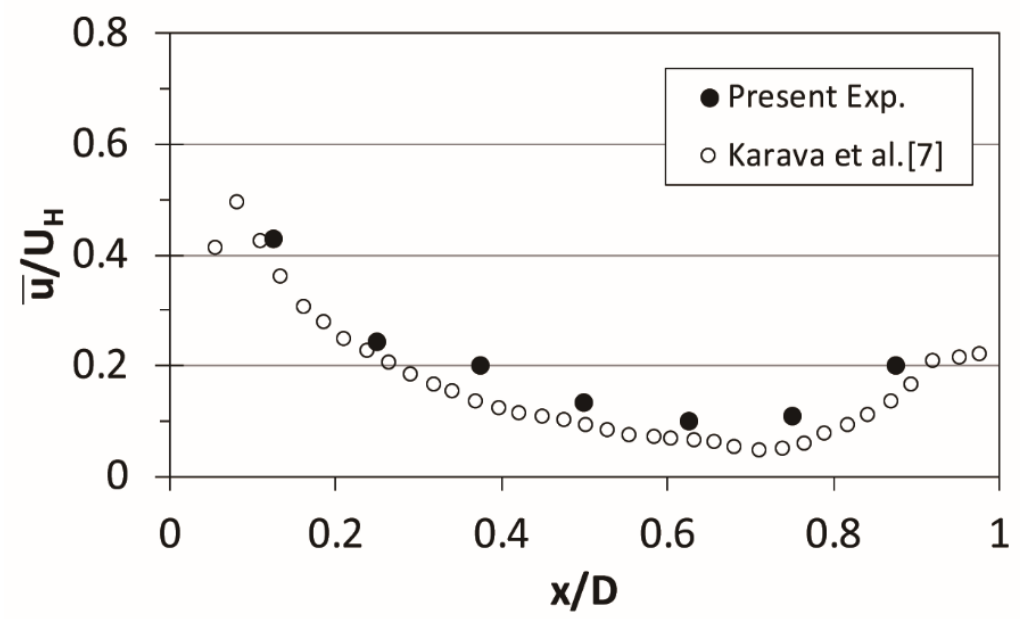

Fig. 7. Comparison of experimental results for streamwise velocity ratio $\bar{u} / U_{H}$ along centerline of unsheltered building. 

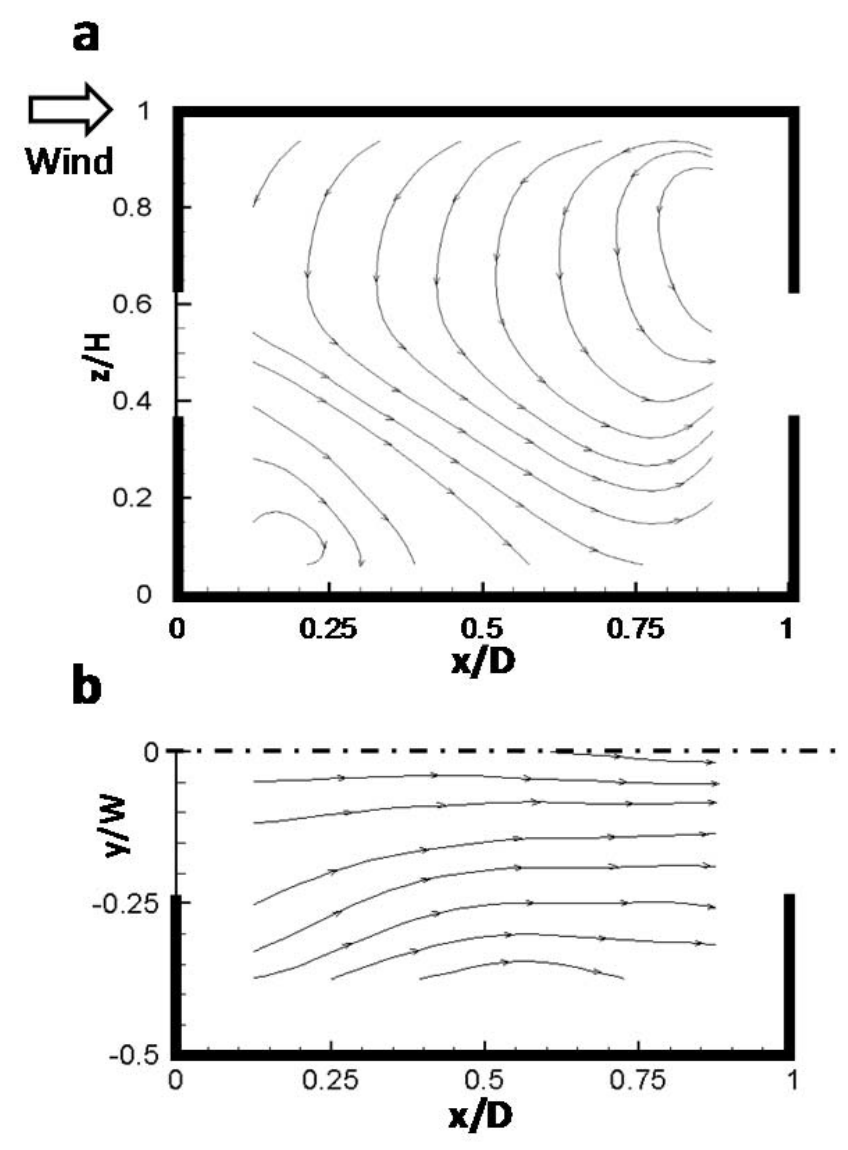

Fig. 8. Time-averaged streamlines in (a) vertical center section and (b) horizontal section $(\mathrm{z} / \mathrm{H}$ $=0.5)$ of unsheltered building.
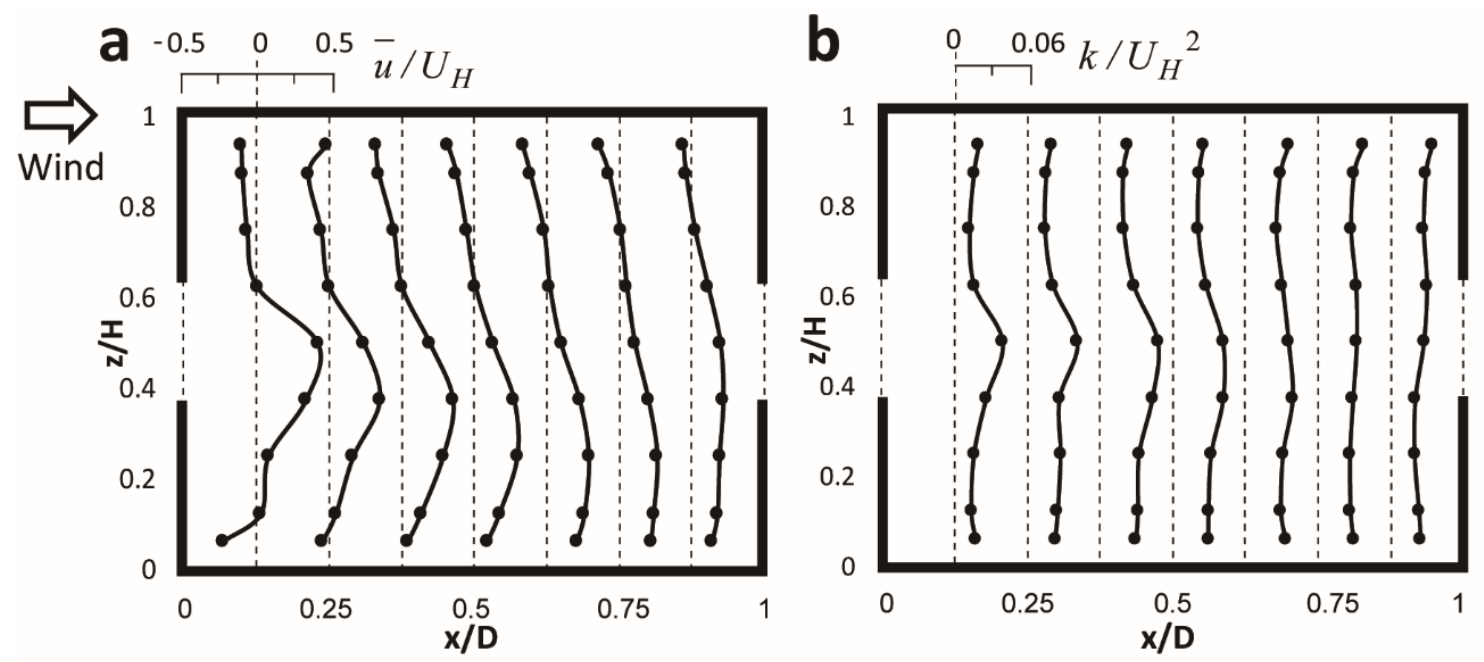

Fig. 9. Vertical profiles of (a) time-averaged streamwise velocity $\bar{u} / U_{H}$ and (b) turbulent kinetic energy $k$ in vertical center section of unsheltered building. 


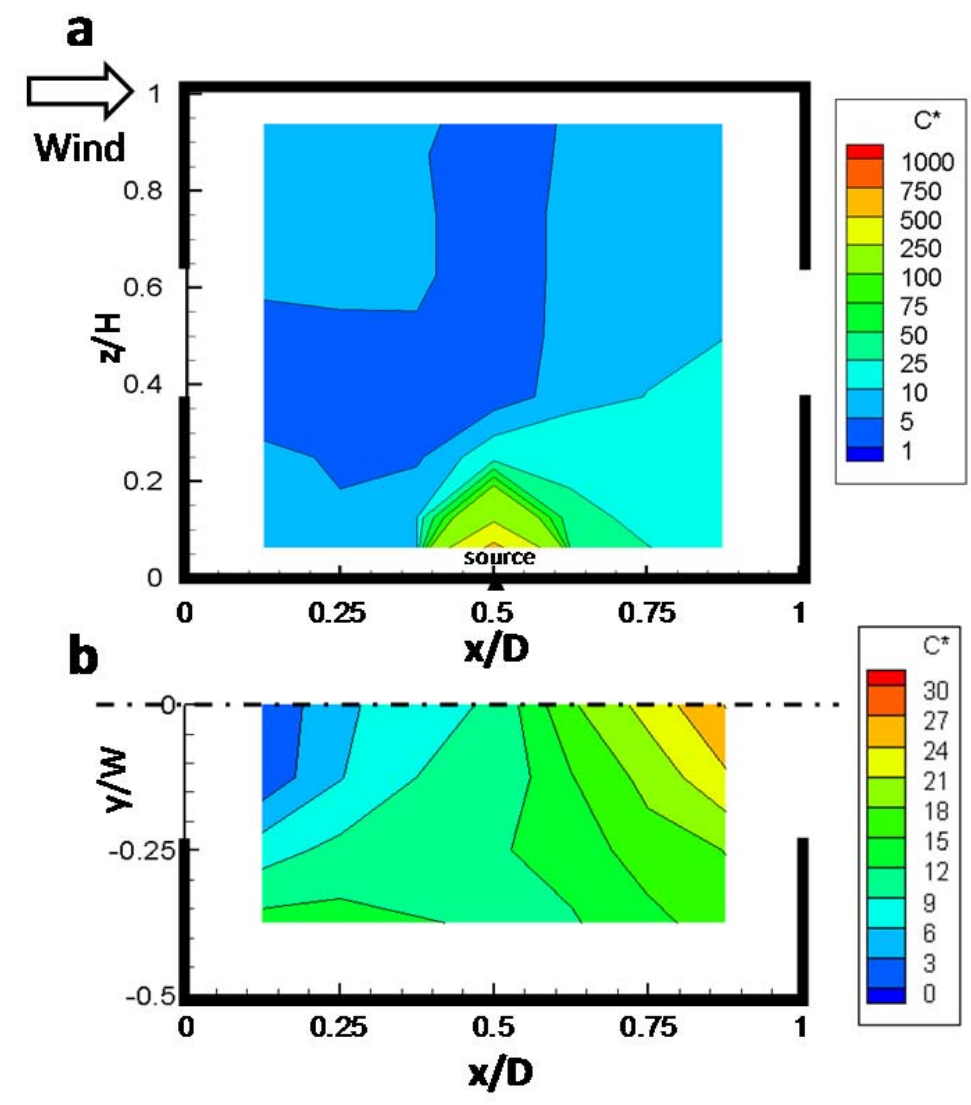

Fig. 10. Contours of time-averaged concentration $\bar{c} / C_{0}$ in (a) vertical center section and (b) horizontal section $(\mathrm{z} / H=0.5)$ of unsheltered building.
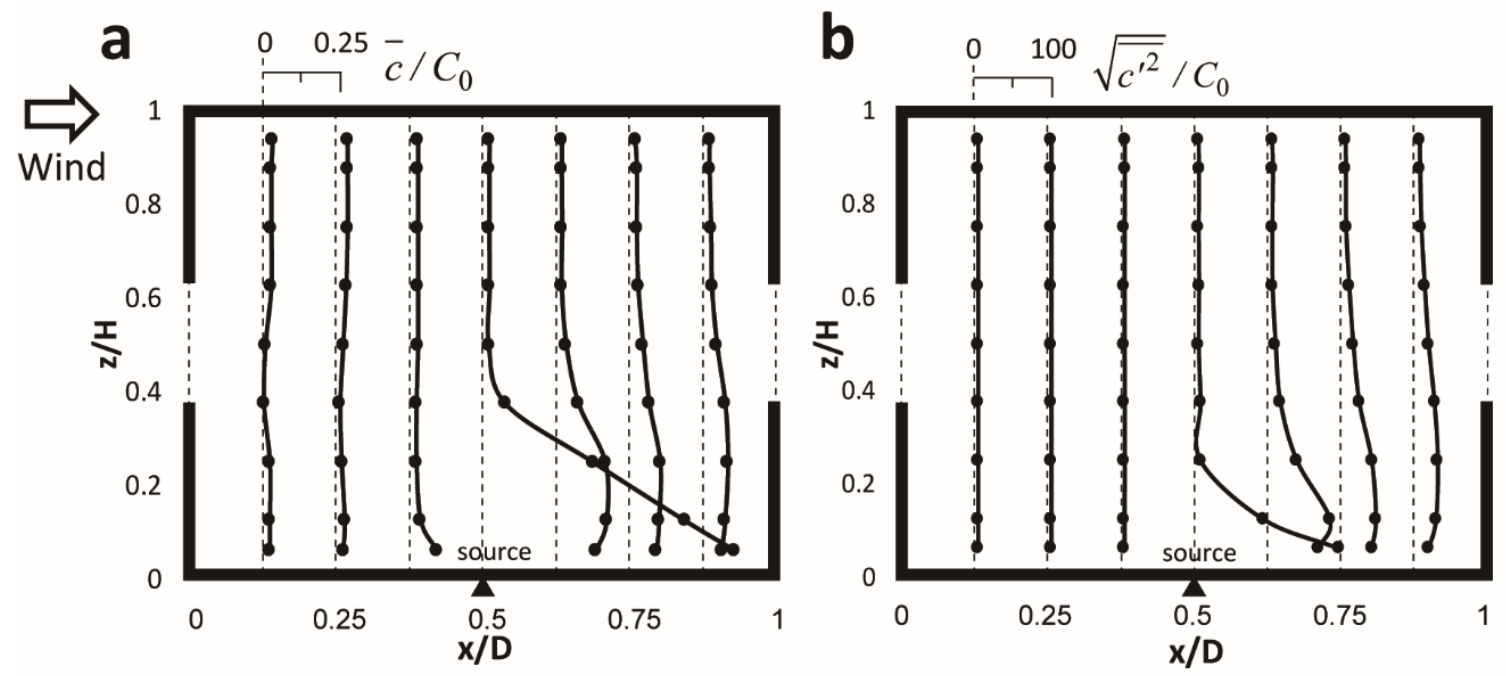

Fig. 11. Vertical profiles of (a) time-averaged concentration $\bar{c} / C_{0}$ and (b) root-mean-square value of concentration fluctuation $\sqrt{\overline{c^{\prime 2}}} / C_{0}$ in vertical center section of unsheltered building. 

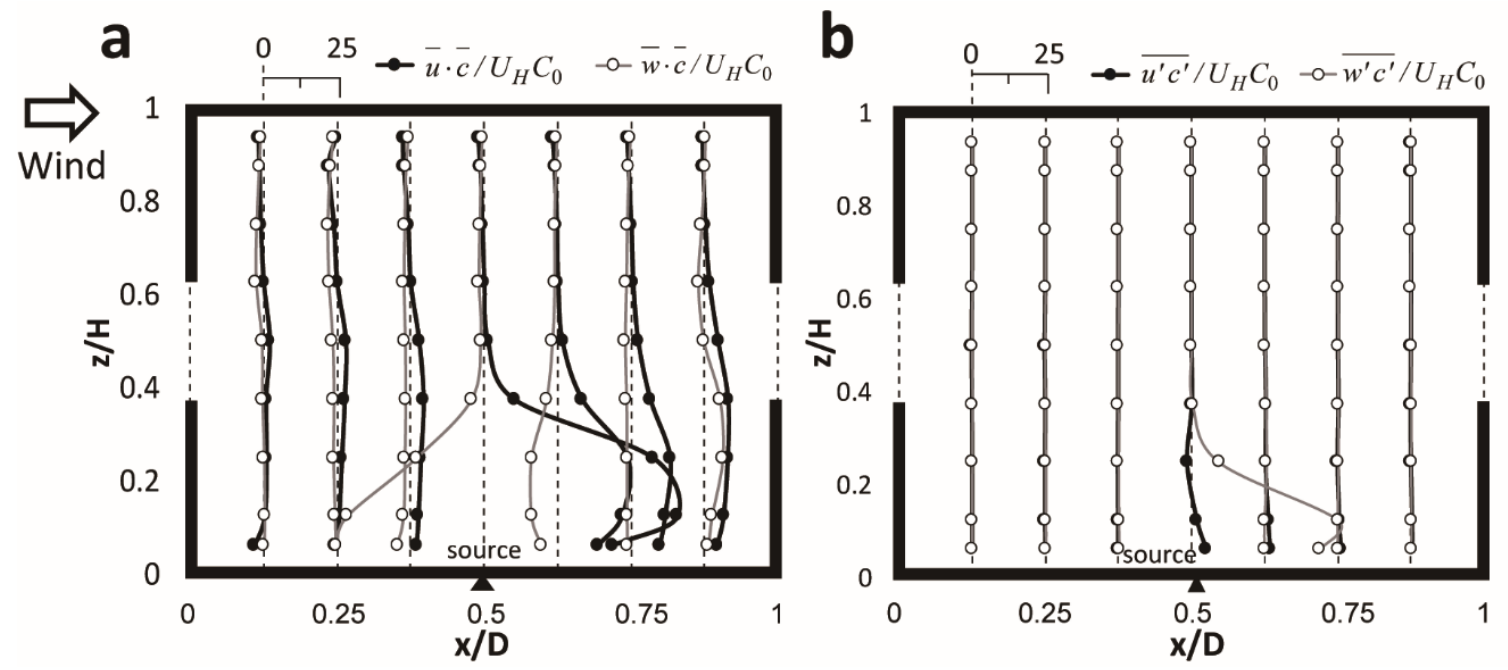

Fig. 12. Vertical profiles of (a) advective scalar fluxes and (b) turbulent scalar fluxes in vertical section of unsheltered building.
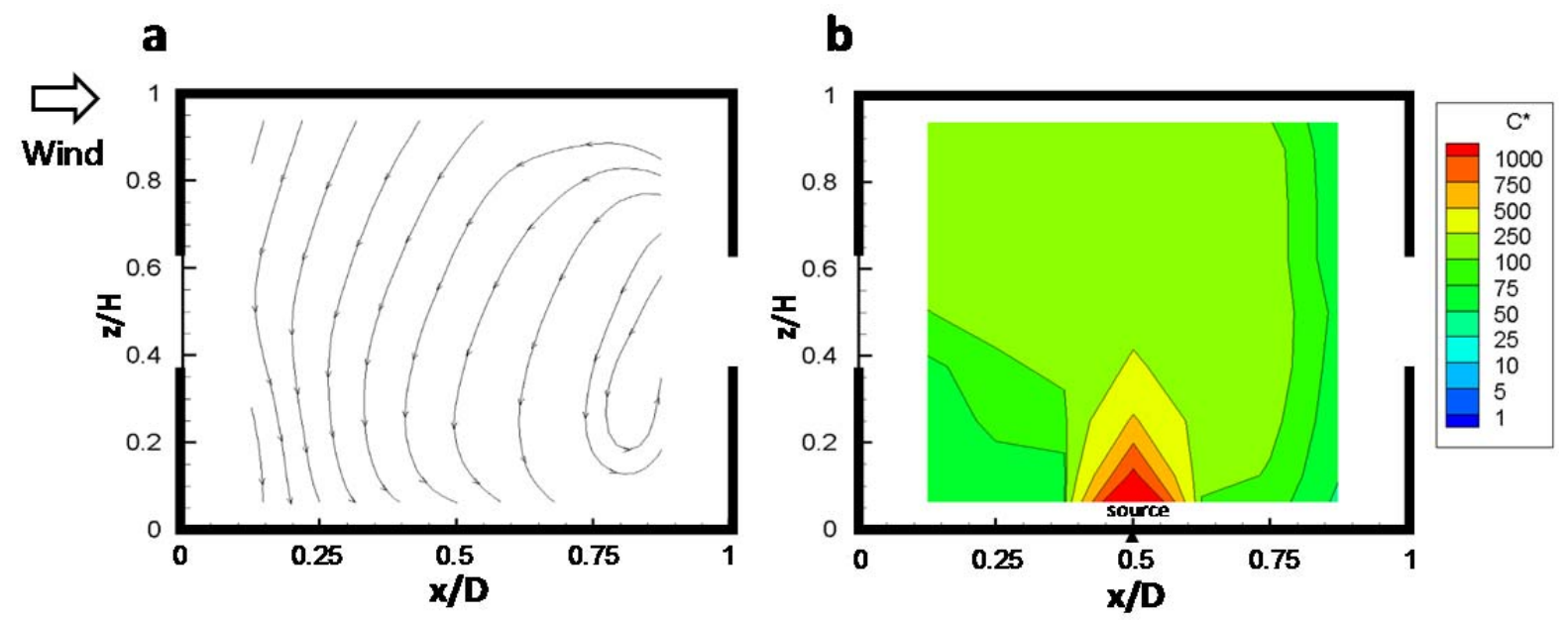

Fig. 13. (a) Streamlines and (b) time-averaged concentration $\bar{c} / C_{0}$ (b) in vertical center section of sheltered building. 

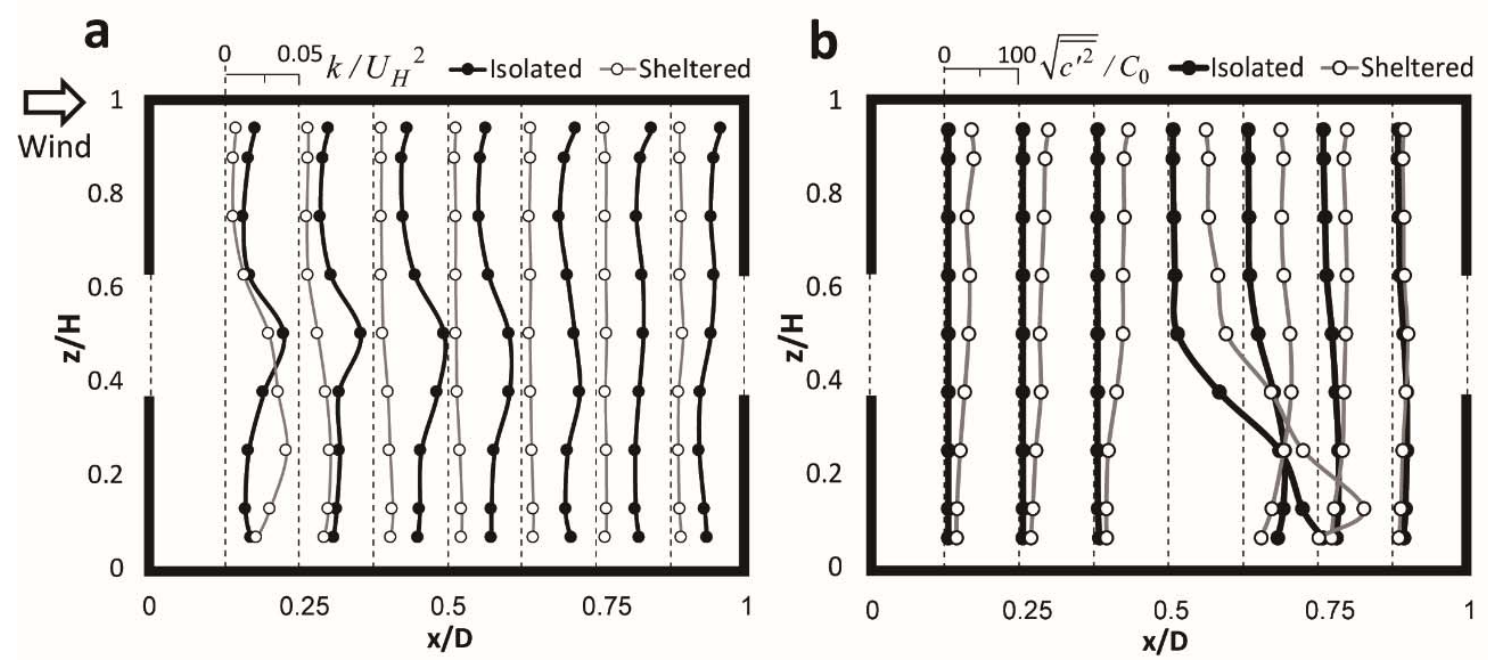

Fig. 14. Vertical profiles of (a) turbulent kinetic energy $k / U_{\mathrm{H}}{ }^{2}$ and (b) RMS values of concentration fluctuation $\sqrt{\overline{c^{\prime 2}}} / C_{0}$ in vertical center section for isolated (unsheltered) and sheltered building. 